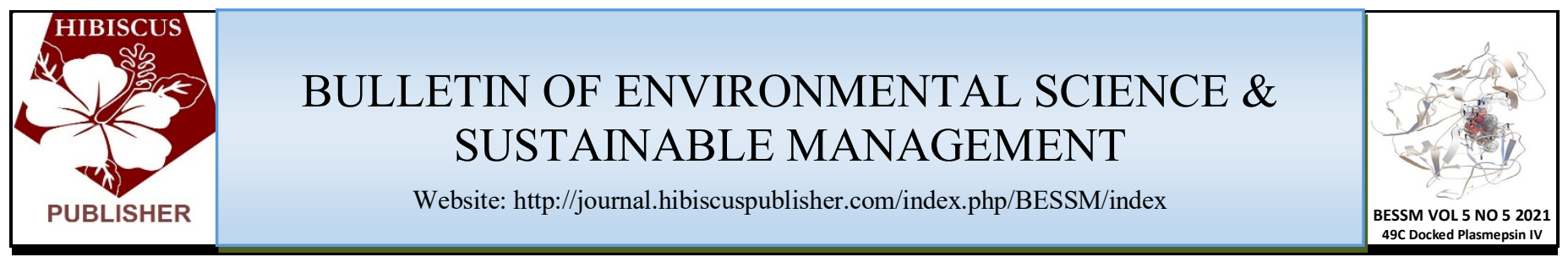

\title{
Kinetic Analysis of the Adsorption of Cibacron Blue onto Bean Peel
}

\author{
Ain Aqilah Basirun ${ }^{1}$ and Mohd Yunus Shukor ${ }^{1 *}$ \\ ${ }^{1}$ Department of Biochemistry, Faculty of Biotechnology and Biomolecular Sciences, Universiti Putra Malaysia, \\ 43400 UPM Serdang, Selangor, Malaysia. \\ *Corresponding author: \\ Department of Biochemistry, \\ Faculty of Biotechnology and Biomolecular Sciences, \\ Universiti Putra Malaysia, \\ 43400 UPM Serdang, \\ Selangor, \\ Malaysia. \\ Email: hahadiza@gsu.edu.ng
}

\section{HISTORY \\ Received: $4^{\text {th }}$ Aug 2021 \\ Received in revised form: $15^{\text {th }}$ Oct 2021 \\ Accepted: $12^{\text {th }}$ Dec 2021}

\section{KEYWORDS}

Kinetics

Cibacron blue

Cibacron b

Pseudo-2 ${ }^{\text {nd }}$ order

\begin{abstract}
Biosorption is a kind of sorption technology in which the sorbent is derived from a biological source. At the moment, biosorption is seen as a simple, cost-effective, and environmentally friendly process that might be employed as a viable alternative to conventional techniques of pollution removal. When it comes to improper textile waste disposal, it falls under one of the branches of bioremediation that is used to reduce contamination in the setting of improper textile waste disposal. The sorption isotherm of Cibacron Blue onto bean peel were analyzed using three models - pseudo- $1^{\text {st }}$, pseudo- $2^{\text {nd }}$ and Elovich, and fitted using non-linear regression. The Elovich model was the poorest in fitting the curve based on visual observation and the best was pseudo$2^{\text {nd }}$ order based on statistical analysis such as root-mean-square error (RMSE), adjusted coefficient of determination $\left(\operatorname{adj} R^{2}\right)$, bias factor $(\mathrm{BF})$, accuracy factor $(\mathrm{AF})$, corrected AICc (Akaike Information Criterion), Bayesian Information Criterion (BIC) and Hannan-Quinn information criterion (HQC). Nonlinear regression analysis using the pseudo- $2^{\text {nd }}$ order model gave values of equilibrium sorption capacity $q_{e}$ of $6.164 \mathrm{mg} / \mathrm{g}(95 \%$ confidence interval from 5.918 to 6.410$)$ and a value of the pseudo- $2^{\text {nd }}$-order rate constant, $k_{2}$ of 0.034 (95\% confidence interval from 0.024 to 0.045 ). Further analysis is needed to provide proof for the chemisorption mechanism usually tied to this kinetic.
\end{abstract}

\section{INTRODUCTION}

The textile industry divides fibre manufacture into two categories: dry procedures and wet processes. The wet process, which involves sizing and de-sizing, sourcing, bleaching, dyeing, and finishing, is the more significant of the two processes. Those stages need the use of a large amount of pure water, resulting in significantly contaminated effluents. The dying process is an important factor in ensuring that textile goods be effectively exchanged. Aside from the design and the appealing appearance, the consumer is often seeking for several common product qualities such as great optical fixation, abruptness, and cleanliness both during the initial purchasing process and after lengthy usage. Colorants for fibres must be very specific, colorconsistent, fading-resistant, and reasonably priced [1].

Advanced dyeing technology consists of a few stages that are chosen for use in supplies based on the origin of the fibre and the properties of the dyes and pigments, such as chemical constitution, group, commercial affordability, adhesive matters consistent with the desired substance to be coloured, and financial considerations. There are two types of advanced dyeing technology: dyeing and pigmenting. The dyeing procedures have altered from time to time, although they have not advanced much. The technique is separated into three parts, which are as follows: preparation, dyeing, and finishing [2-4].

Preparation is the process of cleaning the materials of any unwanted contamination before tinting them. The technique is done out using alkaline washing and detergents, as well as enzymes. It is possible to remove the colour origin of the fabric by using hydrogen peroxide or a chlorine-based product. An optical brightening agent is used on white materials to make them seem brighter [1] . The most significant aspect of dyeing operations is the application of dyes to textile surfaces. An appropriate dye that sticks to the textile is used to colour different types of materials. During this process, a variety of colourants and chemical fixation agents, such as surfactants, acids, alkalis, or bases; electrolytes; carriers; flattening and stimulating agents (chelation); emulsifiers; and softening agents, are used to achieve a uniform colour depth and appropriate colour fastness for the fabric. This method comprises first diffusing the dye into the liquid phase, then adsorption on the outer surface of the fibres, and lastly diffusion and adsorption on the interior surface of the 
fibres, as previously described. To achieve the criteria, a variety of fastness qualities may be required, depending on the intended end use of the textiles under consideration. To achieve these qualities, many types of dyes and chemical additives are employed in the finishing phase of the manufacturing process, which is finished at the conclusion of the manufacturing process [5].

It is estimated that textiles would use $90 \%$ of all dyes generated, with the remaining $10 \%$ being utilised in a range of other sectors such as leather, paper, plastic, and chemical manufacturing. According to World Health Organization (WHO) estimates, about 280000 tonnes of textile dyes are emitted as industrial effluent globally each year. Colorants, such as dyes and pigments, are among the most dangerous water pollutants because some dyes are poisonous or carcinogenic to aquatic life and humans even at low quantities when discharged with industrial effluents. When some dyes are emitted with industrial effluents, they have mutagenic, teratogenic, and carcinogenic effects on aquatic life and humans even at low quantities. Textile finishing refers to the last stage of the dyeing process, which includes the stages of washing, bleaching, printing, and generating a finished textile product. This subsector is made up of both commission finishing and integrated textile industries.

Textile finishing is a diverse industry due to the variety of raw materials, manufacturing techniques, and finished products accessible. Instead of being seen as a homogeneous treatment sequence, it should be viewed as a collection of unit operations that may be utilised in the manufacture of a textile product, depending on the end user's needs. Finishing is the use of chemical substances to improve the appearance and feel of a textile. Textiles that are resistant to water and stains, for example, may be treated with permanent press processes such as waterproofing and softening, as well as antistatic protection, to enhance their longevity [6-8].

Biosorption techniques are critical in a range of biotreatment procedures, both environmental and conventional. Biological materials such as living or dead bacteria and their components, marine algae, plants, agricultural wastes, and naturally occurring residents are intended to remove or recover organic or inorganic matter from solution. In a previous study, the sorption of Cibacron Blue onto bean peel was studied using linearized kinetic models which disrupt the error structure of the data and hindered efficient inference and comparison with current biosorption data that have begun to capitalize on the computing power that allow nonlinear regression to be carried out at ease. Correct assignment of the kinetics and isotherms of biosorption is critical for understanding the mechanism of biosorption. This is especially true for understanding the mechanism of biosorption.

The use of linearization to smooth out a clearly nonlinear curve causes the error structure of the data to be disrupted. This makes estimating the uncertainty of the parameters of the kinetics, which is generally provided in the form of a 95 percent confidence interval range, much more challenging [9]. Aside from that, the linearization procedure results in the introduction of error into the independent variable as well. Additionally, changes in the weights assigned to each data point may occur, which typically results in discrepancies in the fit parameter values between both the linear and nonlinear versions of the kinetics model, depending on the data set [10]. Thus, the aim of this study is to remodel the data using nonlinear regression.

\section{METHODS}

\section{Data acquisition and fitting}

Data from Figure 4 from a published work [11] were digitized using the software Webplotdigitizer 2.5 [12]. The data were then nonlinearly regressed using the curve-fitting software CurveExpert Professional software (Version 1.6). Digitization using this software has been acknowledged for its reliability $[13,14]$. The data were then nonlinearly regressed using the curve-fitting software CurveExpert Professional software (Version 1.6) using several models (Table 1).

Table 1. Kinetic models utilized in this study.

\begin{tabular}{|c|c|c|}
\hline Model & Equation & Reference \\
\hline Pseudo- $1^{\text {st }}$ order & $q_{t}=q_{e}\left(1-e^{-K_{1 t}}\right)$ & {$[15]$} \\
\hline Pseudo- $2^{\text {nd }}$ order & $K_{2} q_{e}^{2} t$ & [16] \\
\hline Elovich & $\begin{aligned} q_{t} & =\overline{\left(1+K_{2} q_{e} t\right)} \\
q_{t} & =\frac{1}{\rho \ln \rho}+\frac{1}{}\end{aligned}$ & [17] \\
\hline
\end{tabular}

\section{Statistical analysis}

A battery of statistical discriminatory tests such as corrected AICc (Akaike Information Criterion), Bayesian Information Criterion (BIC), Hannan and Quinn's Criterion (HQ), RootMean-Square Error (RMSE), bias factor (BF), accuracy factor $(\mathrm{AF})$ and adjusted coefficient of determination $\left(R^{2}\right)$ were utilized in this work.

The RMSE was calculated according to Eq. (1), [9], and smaller number of parameters is expected to give a smaller RMSE values. $n$ is the number of experimental data, $O b_{i}$ and $P d_{i}$ are the experimental and predicted data while $p$ is the number of parameters.

$R M S E=\sqrt{\frac{\sum_{i=1}^{n}\left(P d_{i}-O b_{i}\right)^{2}}{n-p}}$

As $R^{2}$ or the coefficient of determination ignores the number of parameters in a model, the adjusted $R^{2}$ is utilized to overcome this issue. In the equation (Eqns. 2 and 3), the total variance of the y-variable is denoted by $s_{y}^{2}$ while RMS is the Residual Mean Square.

$$
\begin{aligned}
& \operatorname{Adjusted}\left(R^{2}\right)=1-\frac{R M S}{s_{Y}^{2}} \\
& \text { Adjusted }\left(R^{2}\right)=1-\frac{\left(1-R^{2}\right)(n-1)}{(n-p-1)}
\end{aligned}
$$

The AICc is calculated as follows (Eqn. 4), where $p$ signifies the quantity of parameters and $n$ signify the quantity of data points. To handle data having a high number of parameters or a smaller number of values corrected Akaike information criterion (AICc) is utilized [18].A model with a smaller value of AICc is deemed likely more correct [18]. The Akaike Information Criterion (AIC) is based on the information theory. It balances between the goodness of fit of a particular model and the complexity of a model [19].

$$
A I C c=2 p+n \ln \left(\frac{R S S}{n}\right)+2(p+1)+\frac{2(p+1)(p+2)}{n-p-2}
$$


Aside from AICc, Bayesian Information Criterion (BIC) (Eqn. 5) is another statistical method that is based on information theory. This error function penalizes the number of parameters more strongly than AIC [20].

$B I C=n \cdot \ln \frac{R S S}{n}+k \cdot \ln (n)$

A further error function method based on the information theory is the Hannan-Quinn information criterion (HQC) (Eqn. 6). The HQC is strongly consistent unlike AIC due to the $\ln \ln n$ term in the equation [18];

$H Q C=n \times \ln \frac{R S S}{n}+2 \times k \times \ln (\ln n)$

(Eqn. 6)

Further error function analysis that originates from the work of Ross [21] are the Accuracy Factor (AF) and Bias Factor (BF). These error functions test the statistical evaluation of models for the goodness-of-fit but do not penalize for number of parameter (Eqns. 7 and 8).

$$
\begin{aligned}
& \text { Bias factor }=10^{\left(\sum_{i=1}^{n} \log \frac{\left(P d_{i} / O b_{i}\right)}{n}\right)} \\
& \text { Accuracy factor }=10^{\left(\sum_{i=1}^{n} \log \frac{\left|\left(P d_{i} / O b_{i}\right)\right|}{n}\right)}
\end{aligned}
$$

Another error function analysis is the evidence ratio regarding the difference between the two lowest AICc values (Eqn. 9), where if it is the same, then each model will have an equal chance of being true. If the difference in AICc scores is 6.0, model A has a $95 \%$ chance of being correct, making it $20(95 / 5)$ times more likely than model B to be correct [9].

$$
P_{A}=\frac{e^{0.5 \Delta}}{1+e^{0.5 \Delta}}
$$

\section{RESULTS AND DISCUSSION}

People have used dyes in their everyday life for a variety of purposes since 3000 B.C. Egypt, Romania, and India are just a few of the nation's having a strong dying industry. Color compounds are regarded as important pollutants and are sometimes referred to as a 'discernible contaminant.' It is estimated that over 10103 tonnes of various commercial dyes and pigments are produced worldwide each year, with the United States producing more than 70104 tonnes (Slama et al., 2021; Garg, 2004).

In ancient times, textiles were coloured using local dyes, but the colour palette was restricted, and the range of colours was limited. Furthermore, the colour fastness of the material deteriorates with time as a consequence of repeated washing and exposure to sunlight (Kant, 2011). To obtain the intricate hue, mordants were utilised instead, resulting in a time-consuming dyeing technique. Artificial dyes, initially invented by W. H. Perkins in 1856, allowed for the production of a large range of coloured fabrics in a short amount of time and in a greater spectrum of colours and tints.
As a consequence, the "dye application" sector is now a multibillion-dollar business. Natural dyes, on the other hand, are increasing popularity across the world as a consequence of the negative and unpleasant effects that synthetic colours have on all forms of life. Dyes have the potential to be toxic and have a major negative impact on effluent value. The natural dye painting method required a large volume of water. The quantity of dye that will be used is expected to be almost equal to or double the amount of coloured fibre. When dyeing a garment, about $80 \%$ of the colourant stays on the cloth, while the remaining $20 \%$ is flushed away as effluent (Essawy et al., 2008). According to the textile industry, this sector accounts for around $22 \%$ of total industrial wastewater created in the country (Tan et al., 2008).

The absorption kinetics data were analyzed using three models - pseudo- $1^{\text {st }}$, pseudo- $2^{\text {nd }}$ and Elovich, and fitted using non-linear regression. The Elovich model was the poorest in fitting the curve based on visual observation followed by the Pseudo-1st order (Figs. 1-3). Statistical analysis based on rootmean-square error (RMSE), adjusted coefficient of determination $\left(\operatorname{adj} R^{2}\right)$, bias factor $(\mathrm{BF})$, accuracy factor $(\mathrm{AF})$, corrected $\mathrm{AICc}$ (Akaike Information Criterion), Bayesian Information Criterion (BIC) and Hannan-Quinn information criterion (HQC) that showed that the pseudo-2nd-order model was the best (Table 2) which was the same finding from the original published work.

The calculated evidence ratio was 155 with an AICc probability value of 0.99 indicating that the best model was at least 155 times better than the nearest best model, which was pseudo- $1^{\text {st }}$. Further analysis is needed to provide proof for the mechanism usually tied to this kinetic. Nonlinear regression analysis using the pseudo- $2^{\text {nd }}$ order model gave values of equilibrium sorption capacity $q_{e}$ of $6.164 \mathrm{mg} / \mathrm{g}(95 \%$ confidence interval from 5.918 to 6.410 ) and a value of the pseudo- $2^{\text {nd }}$-order rate constant, $k_{2}$ of 0.034 (95\% confidence interval from 0.024 to 0.045). In comparison, the published work reported an equilibrium sorption capacity $q_{e}$ of $6.57 \mathrm{mg} / \mathrm{g}$ and a value of the pseudo- $2^{\text {nd }}$-order rate constant, $k_{2}$ of 0.0199 [11]. Further analysis is needed to provide proof for the chemisorption mechanism usually tied to this kinetic.

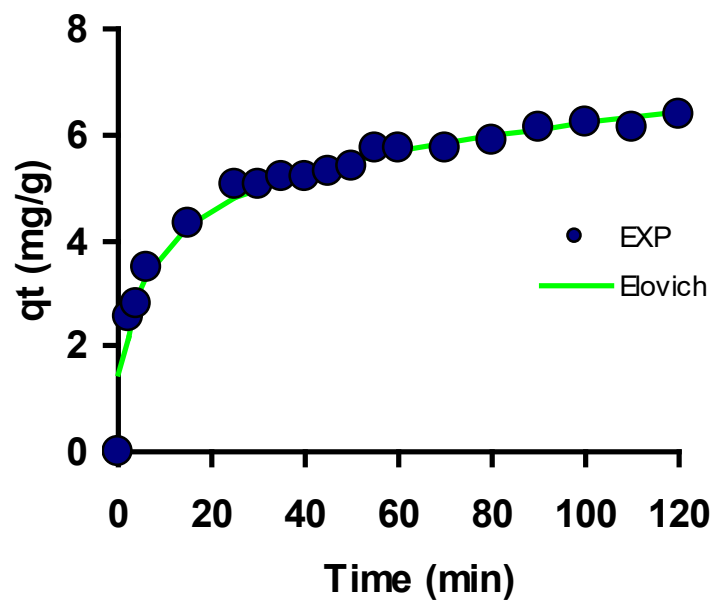

Fig. 1. Kinetics of the sorption of Cibacron Blue onto bean peel as modelled using the Elovich model. 


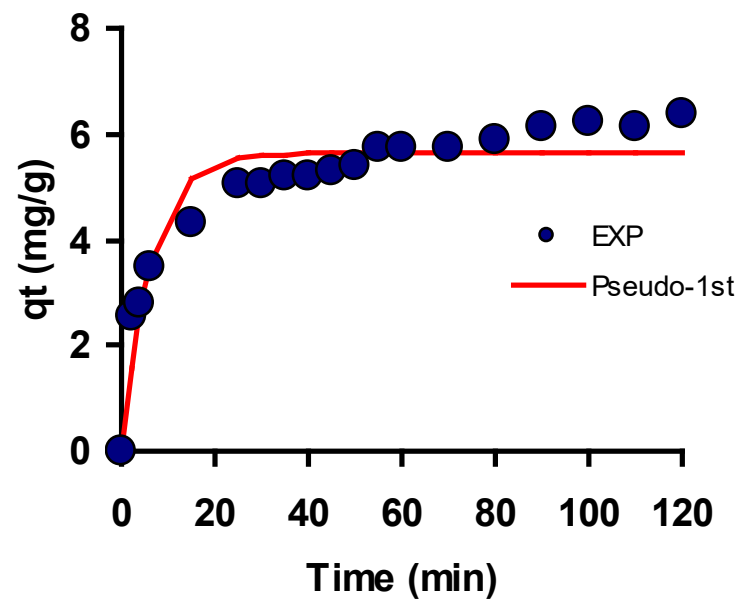

Fig. 2. Kinetics of the sorption of Cibacron Blue onto bean peel as modelled using the pseudo- $1^{\text {st }}$ order model.

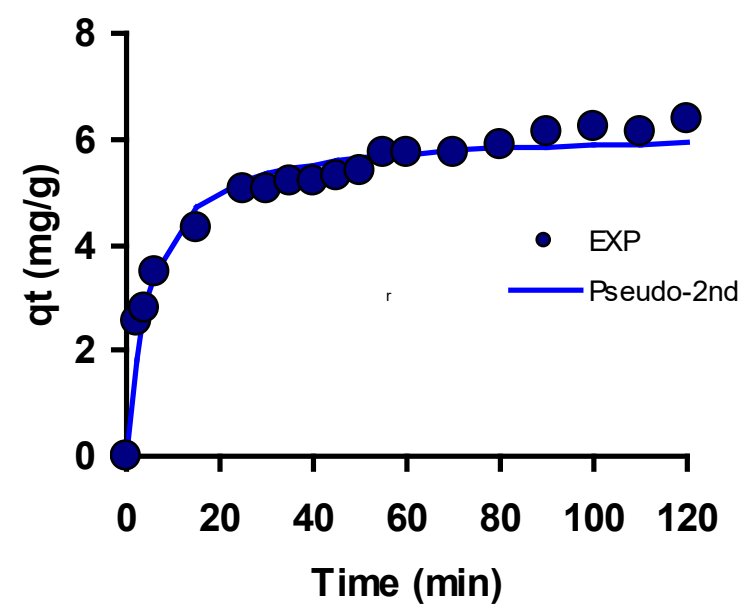

Fig. 3. Kinetics of the sorption of Cibacron Blue onto bean peel as modelled using the pseudo- $2^{\text {nd }}$ order model.

Table 2. Error function analysis of regressed models.

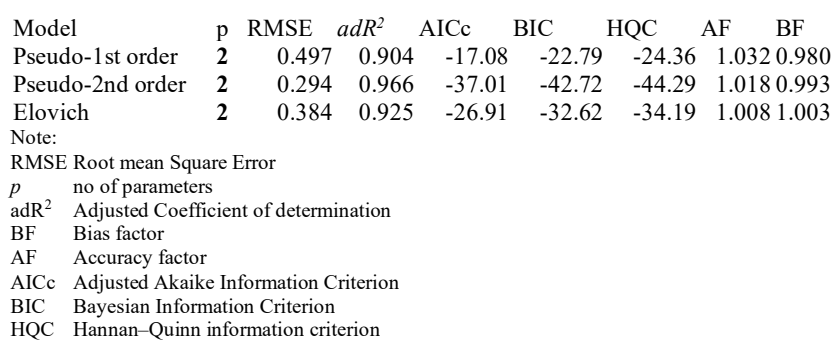

Using kinetic models to examine experimental data, researchers have been able to better understand the mechanism of sorption as well as probable rate-controlling phases, such as chemical reactions and mass transport mechanisms. Incorporating the pseudo-1st order equation, the pseudo-2nd order equation, and the Elovich equation, these kinetic models yielded the best results. Before the pseudo first-order process can proceed, the adsorbate concentration must be saturated. This has the effect of maintaining the adsorbate concentration at a constant level, which in turn ensures that the adsorbate is absorbed at a steady rate. The rate is inversely proportional to particle size, distribution coefficient, and film thickness when it is controlled by film diffusion. If both reactants are present in the solution, then the rate-limiting phase of diffusion will be referred to as physisorption (physical exchange) [22-25]. Pseudo- ${ }^{\text {nd }}$ order as the best model in dye biosorption are numerous [1,26-37] and maybe related to the robustness of the mathematical equation for this model $[24,38,39]$.

The rate-controlling step is controlled by the chemical reaction when it is driven by a pseudo second order reaction, and this is referred to as chemisorption (chemical absorption). A second-order reaction happens when this occurs at low adsorbate/adsorbent ratio and two competing second-order reactions happen at higher adsorbate/selective sorbent ratios [40]. However, additional evidence is needed to support this conclusion, such as the evaluation of activation energies obtained by re-running the experiment at various temperatures, and an examination of procedure rates in regards to adsorbent particle size, as well as their reliance on the adsorbent's particle size [41]

\section{CONCLUSION}

In conclusion, the Cibacron Blue onto bean peel was successfully modelled using three models-pseudo- $1^{\text {st }}$, pseudo- $2^{\text {nd }}$ and Elovich, and fitted using non-linear regression. Statistical analysis based on root-mean-square error (RMSE), adjusted coefficient of determination (adj $\left.R^{2}\right)$, bias factor $(\mathrm{BF})$, accuracy factor (AF), corrected AICc (Akaike Information Criterion), Bayesian Information Criterion (BIC) and Hannan-Quinn information criterion (HQC) showed that the pseudo- $2^{\text {nd }}$ order model was the best model. Nonlinear regression analysis using the pseudo- $2^{\text {nd }}$ order model gave values of equilibrium sorption capacity $q_{e}$ of $6.164 \mathrm{mg} / \mathrm{g}$ (95\% confidence interval from 5.918 to 6.410$)$ and a value of the pseudo- $2^{\text {nd }}$-order rate constant, $k_{2}$ of 0.034 (95\% confidence interval from 0.024 to 0.045 ). Further analysis is needed to provide proof for the mechanism usually tied to this kinetic. The nonlinear regression method allows for the parameter values to be represented in the $95 \%$ confidence interval range which can better allow comparison with published results.

\section{ACKNOWLEDGEMENT}

This research is funded under the Fundamental Research Grant Scheme (FRGS/1/2017/TK05/UPM/02/11) by the Ministry of Higher Education (MOHE) Malaysia.

\section{REFERENCES}

1. Gürel L. Biosorption of textile dye reactive blue 221 by capia pepper (Capsicum annuum L.) seeds. Water Sci Technol. 2017;75(8):1889-98.

2. Ekanayake MS, Udayanga D, Wijesekara I, Manage P. Phytoremediation of synthetic textile dyes: biosorption and enzymatic degradation involved in efficient dye decolorization by Eichhornia crassipes (Mart.) Solms and Pistia stratiotes L. Environ Sci Pollut Res. 2021;28(16):20476-86.

3. Tegli S, Cerboneschi M, Corsi M, Bonnanni M, Bianchini R. Water recycle as a must: Decolorization of textile wastewaters by plantassociated fungi. J Basic Microbiol. 2014;54(2):120-32.

4. Pearce CI, Lloyd JR, Guthrie JT. The removal of colour from textile wastewater using whole bacterial cells: A review. Dyes Pigments. 2003;58(3):179-96.

5. Ekambaram SP, Perumal SS, Rajendran D, Samivel D, Khan MN New approach of dye removal in textile effluent: A cost-effective management for cleanup of toxic dyes in textile effluent by water hyacinth. Methods Pharmacol Toxicol. 2018;(9781493974245):241-67.

6. Wijetunga S, Li X-F, Jian C. Effect of organic load on decolourization of textile wastewater containing acid dyes in 
upflow anaerobic sludge blanket reactor. J Hazard Mater. 2010;177(1-3):792-8.

7. Seyedi ZS, Zahraei Z, Jookar Kashi F. Decolorization of Reactive Black 5 and Reactive Red 152 Azo Dyes by New Haloalkaliphilic Bacteria Isolated from the Textile Wastewater. Curr Microbiol. 2020 Sep 1;77(9):2084-92.

8. Mishra S, Maiti A. Process optimization for effective biodecolourization of Reactive Orange 16 using Chemometric methods. J Environ Sci Health Part A. 2018 Nov 6;

9. Motulsky HJ, Ransnas LA. Fitting curves to data using nonlinear regression: a practical and nonmathematical review. FASEB J Off Publ Fed Am Soc Exp Biol. 1987;1(5):365-74.

10. Tran HN, You S-J, Hosseini-Bandegharaei A, Chao H-P. Mistakes and inconsistencies regarding adsorption of contaminants from aqueous solutions: A critical review. Water Res. 2017 Sep $1 ; 120: 88-116$.

11. Grabi H, Derridj F, Lemlikchi W, Guénin E. Studies of the potential of a native natural biosorbent for the elimination of an anionic textile dye Cibacron Blue in aqueous solution. Sci Rep. 2021 May 6;11(1):9705.

12. Rohatgi.A..WebPlotDigitizer.

http://arohatgi.info/WebPlotDigitizer/app/ Accessed June 2 2014.; 2015.

13. Halmi MIE, Shukor MS, Johari WLW, Shukor MY. Mathematical modelling of the degradation kinetics of Bacillus cereus grown on phenol. J Environ Bioremediation Toxicol. 2014;2(1):1-5.

14. Khare KS, Phelan Jr FR. Quantitative comparison of atomistic simulations with experiment for a cross-linked epoxy: A specific volume-cooling rate analysis. Macromolecules. 2018;51(2):56475 .

15. Lagergren S. Zur theorie der sogenannten adsorption gelöster stoffe (About the theory of so-called adsorption of soluble substances). K Sven Vetenskapsakademiens Handl. 1898;24(4):1-39.

16. Ho YS, McKay G. Pseudo-second order model for sorption processes. Process Biochem. 1999 Jul 1;34(5):451-65.

17. Zeldovich J. Über den mechanismus der katalytischen oxydation von CO an $\mathrm{MnO}_{2}$. Acta Physicochim URSS. 1934;1:364-499.

18. Burnham KP, Anderson DR. Model Selection and Multimodel Inference: A Practical Information-Theoretic Approach. Springer Science \& Business Media; 2002. 528 p.

19. Akaike H. New look at the statistical model identification. IEEE Trans Autom Control. 1974;AC-19(6):716-23.

20. Kass RE, Raftery AE. Bayes Factors. J Am Stat Assoc. 1995 Jun 1;90(430):773-95.

21. Ross T, McMeekin TA. Predictive microbiology. Int $\mathrm{J}$ Food Microbiol. 1994;23(3-4):241-64.

22. Yuan G, Zhao B, Chu KH. Adsorption of fluoride by porous adsorbents: Estimating pore diffusion coefficients from batch kinetic data. Environ Eng Res. 2020;25(5):645-51.

23. Li H, He J, Chen K, Shi Z, Li M, Guo P, et al. Author Response to Comment on: Dynamic Adsorption of Sulfamethoxazole from Aqueous Solution by Lignite Activated Coke. Materials. 2021 Jan;14(4):868.

24. Hu Q, Pang S, Wang D. In-depth Insights into Mathematical Characteristics, Selection Criteria and Common Mistakes of Adsorption Kinetic Models: A Critical Review. Sep Purif Rev. 2021 Jul 1;0(0):1-19.

25. González-López ME, Laureano-Anzaldo CM, Pérez-Fonseca AA, Arellano M, Robledo-Ortíz JR. A Critical Overview of Adsorption Models Linearization: Methodological and Statistical Inconsistencies. Sep Purif Rev. 2021 Aug 1;0(0):1-15.

26. Sathishkumar M, Binupriya AR, Vijayaraghavan K, Yun S-I. Two and three-parameter isothermal modeling for liquid-phase sorption of Procion Blue H-B by inactive mycelial biomass of Panus fulvus. J Chem Technol Biotechnol. 2007;82(4):389-98.

27. Tunali S, Ozcan A, Kaynak Z, Ozcan AS, Akar T. Utilization of the Phaseolus vulgaris L. Waste biomass for decolorization of the textile dye Acid Red 57: Determination of equilibrium, kinetic and thermodynamic parameters. J Environ Sci Health - Part ToxicHazardous Subst Environ Eng. 2007;42(5):591-600.

28. Sun X-F, Wang S-G, Liu X-W, Gong W-X, Bao N, Gao B-Y, et al. Biosorption of Malachite Green from aqueous solutions onto aerobic granules: Kinetic and equilibrium studies. Bioresour Technol. 2008 Jun 1;99(9):3475-83.
29. Akar ST, Özcan AS, Akar T, Özcan A, Kaynak Z. Biosorption of a reactive textile dye from aqueous solutions utilizing an agro-waste. Desalination. 2009;249(2):757-61.

30. Kumar R, Ahmad R. Biosorption of hazardous crystal violet dye from aqueous solution onto treated ginger waste (TGW). Desalination. 2011;265(1-3):112-8.

31. Tan C-Y, Li M, Lin Y-M, Lu X-Q, Chen Z-L. Biosorption of Basic Orange from aqueous solution onto dried A. filiculoides biomass: Equilibrium, kinetic and FTIR studies. Desalination. 2011;266(13):56-62.

32. Zhou Q, Gong W, Xie C, Yang D, Ling X, Yuan X, et al. Removal of Neutral Red from aqueous solution by adsorption on spent cottonseed hull substrate. J Hazard Mater. 2011;185(1):502-6.

33. Wu Y, Jiang L, Wen Y, Zhou J, Feng S. Biosorption of Basic Violet $5 \mathrm{BN}$ and Basic Green by waste brewery's yeast from single and multicomponent systems. Environ Sci Pollut Res Int. 2012 Feb;19(2):510-21.

34. Sánchez-Galván G, Ramírez-Núñez PA. Cationic dye biosorption by Salvinia minima: Equilibrium and kinetics. Water Air Soil Pollut [Internet]. 2014;225(7). Available from https://www.scopus.com/inward/record.uri?eid=2-s2.084902300517\&doi=10.1007\%2fs11270-014-2008$8 \&$ partnerID $=40 \&$ md $5=882 \mathrm{bd} 93 \mathrm{~b} 1 \mathrm{c} 02242$ eaa $60 \mathrm{fc} 79 \mathrm{ed} 17 \mathrm{~d} 3 \mathrm{~b} 1$

35. Guechi E-K, Hamdaoui O. Biosorption of methylene blue from aqueous solution by potato (Solanum tuberosum) peel: equilibrium modelling, kinetic, and thermodynamic studies. Desalination Water Treat. 2016;57(22):10270-85.

36. Veleva H. Biosorption of acid dye using quercus coccifera ash: Characterization and kinetic modeling. Ser Biomech. 2016;30(3):13-9.

37. S R, Lata S, P B. Biosorption characteristics of methylene blue and malachite green from simulated wastewater onto Carica papaya wood biosorbent. Surf Interfaces. 2018 Mar 1;10:197-215.

38. Qiu H, Lv L, Pan B, Zhang Q, Zhang W, Zhang Q. Critical review in adsorption kinetic models. J Zhejiang Univ-Sci A. 2009 May 1;10(5):716-24.

39. Foo KY, Hameed BH. Insights into the modeling of adsorption isotherm systems. Chem Eng J. 2010;156(1):2-10.

40. Qurie M, Khamis M, Manassra A, Ayyad I, Nir S, Scrano L, et al. Removal of $\mathrm{Cr}(\mathrm{VI})$ from aqueous environments using micelle-clay adsorption. Sci World J. 2013;Article ID 942703:7.

41. Khamizov RKh, Sveshnikova DA, Kucherova AE, Sinyaeva LA. Kinetic model of batch sorption processes: Comparing calculated and experimental data. Russ J Phys Chem A. 2018 Oct 1;92:20328 . 